\title{
A CULTURA BRASILEIRA E SEUS DESDOBRAMENTOS NA CULTURA ORGANIZACIONAL: O JEITINHO, A MALANDRAGEM E A IMPORTAÇÃO DOS MODELOS DE GESTÃO.
}

Nilmaer Souza da Silva, Joana Sanches-Justo, Valdecir Cahoni Rodrigues

Universidade do Oeste Paulista - UNOESTE

\section{RESUMO}

Comumente assimilam-se os traços culturais brasileiros de maneira avessa, não considerando a realidade cultural híbrida do Brasil, o que vem a refletir na descaracterização do "Eu" organizacional. Por isso, este trabalho tem por objetivo visualizar os propósitos organizacionais, seus desafios e as megatendências mercadológicas, a fim de entender a cultura social a qual estamos arraigados e, assim, compreender as culturas e fenômenos organizacionais brasileiros. Cabe dizer que a cultura organizacional usada no Brasil baseia-se principalmente em correntes norte-americanas, ou seja, é de fato importada e é aqui, que ocorre o fenômeno "jeitinho". Tomase por conclusão que o "jeitinho brasileiro" é responsável, em certa medida, por fazer com que as tecnologias e os modelos administrativos importados se encaixem da melhor maneira à cultura do país. Assim, o perfil organizacional brasileiro está voltado para o aventureiro, jeitoso, malandro, sempre buscando projetos fáceis e rápidos, adequações, valendo-nos inclusive, do sensualismo.

Palavras-chave: Cultura, estrangeirismo, jeitinho, malandragem, organização.

\section{INTRODUÇÃO E OBJETIVO}

Este trabalho tem por objetivo compreender a forma como a cultura brasileira do jeitinho e da malandragem interferem na cultura organizacional, trazendo desafios, mas também novas formas de compreender as organizações à medida em que se desvela a cultura social à qual estamos submersos. Para tanto, são abordados e discutidos os conceitos de cultura e os traços característicos do brasileiro como o "jeitinho" e a malandragem.

Nesse sentido pode-se observar que a cultura brasileira reflete os vários povos que constituem a demografia desse país sul-americano: indígenas, europeus, africanos, asiáticos, árabes etc. Como resultado da intensa miscigenação de povos, surgiu uma realidade cultural peculiar, que sintetiza as várias culturas.

A palavra cultura possuiu inúmeros significados, todos derivados de sua raiz latina, que se refere à plantação, ao ato de cultivar o solo, à domesticação de determinado cultivo, mas aos poucos foi adquirindo o sentido de "refinamento e domesticação do homem por ele mesmo" (WAGNER, 2010, p.54). O homem "que tem cultura" nada mais é do que aquele que tem interesses que corroboram padrões estipulados e que, conseguintemente, "cultiva" sua 
personalidade de acordo com o contrato social "da moderação dos instintos e desejos "naturais" do homem" (WAGNER, 2010, p.54).

O termo cultura se relaciona à transformação da natureza, sendo esta tanto a natureza da fauna e flora, como também a natureza do homem, sua essência, seus valores e modos de ser, pensar, sentir e agir. Contudo, mais do que um conjunto de regras e de hábitos, cultura significa a construção de significados subdivididos pelo conjunto de pessoas pertencentes a um mesmo grupo social (LAKATOS, 1999).

Por consequência, entende-se por cultura um conjunto complexo de tudo aquilo que constitui a vida em comum nos grupos sociais, ou seja, são modos compartilhados de pensar, de sentir e de agir. As culturas inventam a si mesmas a partir de regras, tradições e convenções compartilhadas que permitem que um grupo signifique seu próprio modo de vida e comunique suas experiências. Todo significado atribuído às experiências necessita de uma base coletivamente construída ou, como exprime Wagner (2010), "inventada". Essa "invenção coletiva" dos significados faz com que seja possível a comunicação entre as pessoas de uma mesma cultura à medida que a construção do significado exige um contexto partilhado, comum ao grupo. Desta maneira, o significado atribuído às coisas só existe dentro de determinado contexto.

"O significado é, pois, produto das relações" (WAGNER, 2010, p.80) dentro de um contexto de convenções partilhadas que, obviamente, não é percebido igualmente por todos, mas gira em torno de uma imagem generalizada do homem e de seus modos de vida. Os contextos definem e criam significados ao fornecerem uma base comum, relacional, que inclui a linguagem, a comunicação, ideologias, a moral, de forma que todas as pessoas pertencentes à mesma cultura concebam de forma semelhante sua ação no mundo.

Entretanto, a importância dada ao termo cultura, para uma organização, é recente. O termo cultura organizacional apareceu, primeiramente, na literatura de língua inglesa nos anos 1960, como sinônimo de clima. O equivalente "cultura corporativa" usado nos idos de 1970 ganhou popularidade após publicação do livro com o mesmo título de Deal e Kennedy, em 1982. Desde então, a literatura técnica específica vem utilizando o tema.

\section{METODOLOGIA}

Baseando-se em abrangente referencial teórico, procura-se analisar e comparar, através de bibliografia concernente ao objetivo proposto, as relações existentes para os termos: cultura e cultura organizacional, circunstanciando por fim, a cultura organizacional brasileira. Adentrando- 
se nos estudos de Wood Jr. e Caldas (1999), DaMatta (1986), Wagner (2010) etc acerca das bases da cultura organizacional brasileira, percebe-se que é necessário antes, entender a cultura préexistente que reflete diretamente nos traços culturais organizacionais, o que então, conduz à conjectura sobre as subdivisões do termo cultura, sejam elas legadas através de temos como "jeitinho brasileiro", "malandragem", dentre outros.

\section{RESULTADOS}

Para Fleury (apud PIRES, 2006, p.84), é possível distinguir três tipos de postura com referência à investigação dos fenômenos culturais das organizações. A primeira seria a empiricista, a do fotógrafo social, e implica considerar a sociedade como a somática de indivíduos e a cultura como a somática de opiniões e comportamentos individuais. A segunda seria a do antropólogo, em que o pesquisador penetra na vida organizacional antes observador. A terceira seria do clínico ou terapeuta, que tem a organização como cliente ou objeto de estudo, e busca obter "insights" que auxiliarão na resolução de queixas por ela apresentadas.

Presume-se dessa colocação que a cultura organizacional em sua amplitude é capaz de desenvolver a ordenação, o controle e a correlação em seu mais completo significado, construindo a identidade organizacional e praticamente trazendo a ocultação das relações de domínio.

Hofstede (citado por PIRES, 2006, p.91) afirma que não se pode tornar inteligível a dinâmica humana nas organizações sem conhecer a cultura e a sociedade na qual ela se insere. Vemos nessa abordagem que não se pode compreender a cultura organizacional sem ter conhecimento da cultura social, como exemplo pode-se dizer da dificuldade em descrever a cultura organizacional de um determinado país se desconhecer as suas crenças, tradições e enfim a sua sociedade no âmbito cultural.

Percebe-se, então, que a cultura de uma organização será um conjunto de características que a diferencia em relação a qualquer outra. Torquato (apud SILVA, 1997, p.03) explica que a cultura organizacional não resulta exclusivamente da estrutura formal da organização, mas também da rede informal, aferida pelas expressões de espontaneidade, descontração e laços informais. Um dos fatores mais importantes a diferenciar a cultura de uma empresa da cultura de outra, é a cultura nacional, os costumes, as crenças e os valores.

Partindo das considerações sobre cultura, organização e cultura organizacional, é que se pode apresentar a contextualização da cultura brasileira, visto que as características culturais do país tendem a se refletir nas culturas organizacionais. Em geral, toda sociedade, em maior ou 
menor medida, filtra e adiciona suas próprias ideias, e tecnologias globalizadas criando suas próprias versões, e é assim também para as organizações que filtram tais ideias, costumes e valores, globalizados, mas já nacionalizados, a sua própria maneira. Vale ressaltar a importância da cultura organizacional uma vez que as estratégias de mudança só poderão ser incorporadas de forma consistente a partir da identificação dos traços culturais e é essencial para a sistematização de modelos e estilos propriamente brasileiros de administrar.

\section{DISCUSSÃO}

Afirmam Wood Jr. e Caldas (1999) que o que colaborou para os traços da cultura brasileira - identificados por eles como permeabilidade e plasticidade - "foi a ausência do orgulho de raça do português, caracterizado pela forte atração pelo sensual e pelo exótico e o seu gosto pela mistura racial" (p. 34).

Calligaris (1996) vai mais além e afirma que a colonização, baseada na exploração das riquezas brasileiras com a única finalidade de levar os bens extraídos para a terra natal, Portugal, fez com que a cultura brasileira se caracterizasse por um povo órfão, sem pai, filhos de uma "mãe violada". Segundo este autor, a cultura brasileira tem em sua gênese a exploração desmedida, a falta de limites e, assim, criou-se o costume de sempre tentar burlar as regras, dando um "jeitinho" que, ao mesmo tempo em que parece cordial, mascara a violência social brasileira.

Estes comportamentos teriam resultado, segundo os autores, nas relações sociais e no comportamento do brasileiro de deixar-se seduzir pelo estrangeiro, seja esse produto ou pessoa. Podem sintetizar que a Patologia de "adoração" aos objetos, fenômenos e metodologias estrangeiras, são oriundas desde o dito "descobrimento" do Brasil, carregado pelos seus "descobridores".

Assim é dado o caminho para aplicação da cultura social no âmbito organizacional, porém, o que muito se vê é a importação de modelos administrativos que são implementados nas organizações e trazidos pelas multinacionais, porém, tais modelos muitas vezes entram em conflito com a sociedade, presente, pois trazem valores culturais diferentes dos já existentes. Tais modelos podem, portanto, fracassar ou não apresentar resultados satisfatórios, justamente por não apresentarem bases em alguns traços básicos da cultura brasileira, com isso as organizações, têm descoberto que novas estratégias e práticas gerenciais têm sentido do ponto de vista financeiro ou mercadológico, mas não podem aplicar tais estratégias por deparar-se com valores muito diferentes daqueles pertencentes à cultura organizacional vigente. 
A cultura organizacional usada no Brasil baseia-se principalmente, em correntes norteamericanas. As organizações brasileiras iniciam-se no desenvolvimento individual das características gerais da cultura brasileira, o "jeitinho brasileiro".

O "jeitinho brasileiro" remete a uma constelação de valores específicos que lhe confere o valor que possui atualmente. Entretanto, tentar fazer uma historia do jeitinho mostra-se uma tarefa quase impossível por ser uma forma de procedimento social de aprendizado não expresso claramente a seu respeito, como ocorre no caso das instituições sociais, como família, a igreja, e de rituais como carnaval, festas religiosas, etc.

Portanto, todos os dados aqui apresentados devem ser encarados mais como uma tentativa de sistematizar certo tipo de informação do que uma conceituação propriamente dita. Mas, afinal o que é jeitinho? Para todos, grosso modo, o jeitinho é sempre uma forma especial de resolver algum problema ou situação difícil ou proibida; ou uma solução criativa para alguma emergência, ou seja, sob a forma de conciliação, esperteza ou habilidade. O "jeitinho brasileiro" é, portanto, a arte de ser mais igual que os outros.

Sabemos que "jeito" se distingue de outras categorias afins no universo social brasileiro como favor e corrupção. Todavia, o que distingue o "jeito" do favor ou da corrupção é difícil se estabelecer. Uma forma melhor de entender e distinguir essas categorias é pensá-las como um contínuo que se estende de um pólo, caracterizado como positivo pela sociedade e na qual estaria à categoria favor, até outro, visto como negativo, que se encontraria a corrupção. No meio, o jeito é visto tanto de uma perspectiva negativa como positiva. O que caracteriza a passagem de uma categoria para outra é muito mais o contexto em que a situação ocorre e o tipo de relação existente entre as pessoas envolvidas do que, propriamente, uma natureza peculiar de cada uma.

Para DaMatta (1986, p.104), assim como o "jeitinho brasileiro", a malandragem "trata-se de mesmo um modo - jeito ou estilo - profundamente original e brasileiro de viver". Na nossa sociedade o indivíduo utiliza esse traço quando se depara com uma situação em que o individuo não é reconhecido, e nem valorizado nas suas relações interpessoais, neste momento é que o indivíduo cria uma saída intermediária para resolver a situação.

Tal situação ocorre quando se recebe um "não pode", o mesmo acaba criando um jeitinho para resolver a situação por ser o estilo do brasileiro (DaMATTA, 1986). Sensualismo trata das relações interpessoais mais afetivas. Nesse contexto podemos dizer que o brasileiro coloca sensualismo em suas relações para obter o que deseja, se mostra agradável e cortês. 


\section{CONCLUSÃO}

É conveniente entender como os traços culturais brasileiros podem influenciar diretamente na maneira pelas quais as pessoas são percebidas, geridas, administradas e controladas. Pode-se verificar tal influência no contexto das organizações brasileiras, de modo geral na teoria e aplicação de modelos administrativos importados pelas mesmas, constatando, portanto, a valorização do estrangeiro no mundo organizacional, traço inclusive já analisado por Caldas (1997), em busca pretensiosa pela modernidade, que vem sendo adquirida através da importação dos modelos de gestão aplicados em diversos países.

É possível inferir que muitas desses modelos organizacionais e teorias gerenciais que são elaboradas em outro contexto são reproduzidas como receitas de bolo sem uma análise crítica mais aprofundada e sem uma devida adaptação á realidade brasileira. Esse estrangeirismo, como afirma Motta (2001), dificulta o encontro de soluções para nossos próprios problemas e "que haja um desenvolvimento de modelos de gestão tipicamente nacionais, que levem em conta nossas especificidades na teorização e na análise organizacional".

No mercado internacional as organizações brasileiras tornaram-se nicho de tamanho significativo. Isso se dá, do ponto de vista organizacional, pelo fato de que, para ser aceita e legitimada socialmente, a empresa acaba aplicando rigorosamente práticas ditas "de classe mundial" e "megatendências" no rastro da globalização, sob o pretexto de adquirir competitividade internacional.

Tudo isso é aplicado no trâmite do "jeitinho brasileiro", que faz com que as tecnologias e os modelos administrativos importados se encaixem da melhor maneira à cultura do país, o culmina na busca frenética pelos "modelos alheios" despertando um ciclo infindável de busca de tendências.

Contudo, pode-se dizer que a cultura brasileira cada vez menos é absorvida e replicada aos hábitos da cultura organizacional nacional, enquanto novos hábitos estrangeiros são englobados e passam pelo processo de "aculturação", fazendo com que as organizações acabem por beber insaciavelmente nessa fonte estrangeira, formando um mercado de organizações essencialmente importado.

Definição importante, que auxilia a interpretação do fenômeno "jeitinho" nas organizações, é a de Motta (1999), quando ele apregoa que o jeitinho é típico de quem quer atingir dado objetivo e está avesso às determinações contrárias, quais sejam leis, normas, regras, padrões, etc. Posto isso, é importante salientar que o jeitinho brasileiro é pertinente até na 
medida em que não mascara o problema ou a situação enfrentada, haja vista que, enquanto administradores, é necessário que tenha a percepção de que se determinado processo ou situação organizacional requer muito "jeitinho", é que de fato o todo necessita ser revisto, alterado e redesenhado, considerando que os processos devem atender as demandas organizacionais, e não as organizações atenderem aos processos. Contudo, o jeitinho e a malandragem, não devem ser encarados, a priori, como fenômenos maléficos, considerando que, quando ambos são requeridos, é porque determinada situação de fato requer ações alternativas.

Outrossim, é possível acreditar que as características sociais e passado histórico impulsiona ao entendimento de que o perfil organizacional brasileiro está voltado para o aventureiro, jeitoso, malandro, personificador, evidenciando a exclusão do aspecto pejorativo e maléfico, por sempre buscar projetos fáceis e rápidos, adaptações, adequações, valendo-se, inclusive, do sensualismo. Todavia, não se pode deixar de mencionar que isto muitas vezes atrapalha as soluções efetivas dos problemas, uma vez que são acobertados e não encarados como devem ser. Portando, somos convidados para uma reflexão: enquanto profissionais da área de Administração o que devemos fazer para mudar essa concepção cultural? Devemos mudar?

Fica você leitor, convidado a realizar uma analogia sobre os questionamentos acima, levando-os para sua organização. Evidentemente, o presente trabalho, vem a atenuar a classificação pejorativa do jeitinho e seus assemelhados, impulsionando a reflexão sobre o tema, haja vista que os administradores e demais gestores nem sempre dão a devida importância aos motivos que levam as pessoas a utilizar-se de alguns subterfúgios para se atingir objetivos organizacionais.

Ademais, contextualizando todo o trabalho, desde a formação da cultura brasileira, percorrendo os seus traços culturais na esfera organizacional, até à importação e adoração do estrangeirismo, o que não se podeaceitar enquanto cidadãos brasileiros, acadêmicos e até pela responsabilidade junto à sociedade a que pertencemos, são frases típicas dos pessimistas de plantão: o Brasil não presta! Não tem jeito! Só podia ser no Brasil! Santo de casa não faz milagre!

Temos um compromisso moral com essas questões, pois cabe a cada um verificar potenciais mudanças para a melhora contínua das organizações e, por conseguinte, da nação brasileira. 


\section{REFERENCIAS}

CALLIGARIS, Contardo. Hello Brasil! São Paulo, Escuta, 1996.

DAMATTA, Roberto. O que faz o Brasil, Brasil? Rio de Janeiro: Rocco, 1986.

FLEURY, M.T.; FISCHER, R.M. Cultura e poder nas organizações. São Paulo: Atlas, 1989. In: PIRES, José Calixto de Souza. Cultura Organizacional em Organizações Públicas do Brasil. Rio de Janeiro: RAP, 2006.

MOTTA, Fernando. C.; CALDAS, Miguel. Cultura organizacional e cultura brasileira. São Paulo: Atlas, 2001.

MOTTA, Fernando C. Prestes, Teoria geral da Administração - uma introdução, 3a Edição, Biblioteca Pioneira de Administração Negócio, São Paulo: Pioneira, 1999.

TORQUATO, Gaudêncio. Cultura, poder, comunicação e imagem: fundamentos da nova empresa. São Paulo: Pioneira, 1991. In: SILVA, Luciana Mourão Cerqueira e. Transformações da Cultura Organizacional. São Paulo: USP, 1997.

WAGNER, ROY. A invenção da cultura. São Paulo: Cosac Naify, 2010.

WOOD JR, Thomaz. Transformação e Realidade Organizacional: uma perspectiva brasileira. São Paulo: Atlas, 1999. 